Matija Buzejići ${ }^{1}$ Nikola Slijepčevići, ${ }^{1,2}$, Vlada Živaljevići, ${ }^{1,2}$, Goran Zorić ${ }^{1}$, Božidar Odalovići, ${ }^{1,}$, Katarina Taušanovićt, ${ }^{1,}$ Branislav Rovčanin ${ }^{1}$, Milan Jovanović ${ }^{1}$, Duška Vučen ${ }^{1}$, Boban Stepanović ${ }^{1}$, Ivan Paunović ${ }^{1,2}$

\title{
PRIKAZ SLUČAJA KARCINOMA PARATIROIDNE ŽLEZDE KOD PACIJENATA SA HRONIČNOM BUBREŽNOM INSUFICIJENCIJOM
}

\begin{abstract}
Apstrakt: Uvod Karcinom paratiroidne žlezde je redak tumor endokrinih organa i jedan od najređih tumora u ljudskoj populaciji uopšte. Posebno redak entitet predstavlja karcinom paratiroidne žlezde kod pacijenata sa hroničnom bubrežnom insuficijencijom koji su na hroničnoj hemodijalizi. Patogeneza hiperplazije paratiroidnih žlezda kod pacijenata na hemodijalizi je dobro poznata, za razliku od patogeneze karcinoma paraštitaste žlezde koja još uvek nije u potpunosti rasvetljena. U ovom radu prikazan je slučaj pacijentkinje sa sekundarnim hiperparatiroidizimom kod koje je identifikovan karcinom paratiroidne žlezde.
\end{abstract}

Prikaz bolesnika: Žena stara 67 godina primljena je u Centar radi operativnog lečenja sekundarnog hiperparatiroidizma i palpabilne tumorske mase. Hronična bubrežna insuficijencija nastala je kao posledica dve urološke operacije zbog Renal Cell Carcinoma. Serumski nivo paratiroidnog hormona bio je značajno povišen i iznosio je 1022 ng/L, uprkos terapiji analozima vitamina D. Ultrazvučno preoperativno opisana je promena ispod donjeg pola levog lobusa štitaste žlezde promera 27x29x29 mm. Pacijentkinja je operisana, učinjena je donja leva paratiroidektomija, zbog infiltracije ipsilateralnog lobusa štitaste žlezde učinjena je i leva lobektomija. Postoperativno, nivo paratiroidnog hormona iznosio je $56 \mathrm{ng} / \mathrm{L}$.

Zaključak: Nakon hirurškog lečenja pacijentkinja je bila normokalcemična, nivo paratiroidnog hormona je značajno redukovan. Kod pacijenata sa sekundarnim hiperparatiroidizmom kod kojih se sumnja ili postavi dijagnoza paratiroidnog karcinoma paratiroidektomija je jedini siguran i efikasan vid lečenja.

Ključne reči: karcinom paratiroidne žlezde, hemodijaliza, sekundarni hiperparatiroidizam; paratiroidektomija, hronična bubrežna insuficijencija

Centar za endokrinu hirurgiju, Klinički centar Srbije

2 Medicinski fakultet Univerziteta u Beogradu

3 Medicinski fakultet Univerziteta u Prištini - Kosovska Mitrovica 


\section{UVOD}

Kod pacijenata sa hroničnom bubrežnom insuficijencijom (HBI) kao često prateće stanje nastaje sekundarni hiperparatiroidizam, a hiperplazija paratiroidnih žlezdi je čest patološki nalaz kod ovih pacijenata. Karcinom paratiroidne žlezde je redak entitet kod pacijenata sa HBI. Do sada je u literaturi objavljeno oko 1.000 slučajeva paratiroidnog krcinoma, a od toga oko 34 kod pacijenata sa HBI [1, 2]. Postavljanje dijagnoze paratiroidnog karcinoma je pravi izazov kako za hirurge, tako i za patologe. Kod većine pacijenata prisutni su znaci i simptomi povišenih vrednosti parathormone (PTH), hiperkalcemije, kao i hiperfosfatemije, (bolovi u kostima, svrab).

U Centru za endokrinu hirurgiju u periodu od 7 godina operisano je 7 pacijenata zbog karcinoma paraštitaste žlezde u sklopu primarnog hiperparatiroidizma, a u periodu od 19 godina samo 3 pacijenta sa karcinomom paratiroidee u sklopu sekundarnog hiperparatiroidizma [3]. Do sada su objavljene 3 serije slučajeva sa po dva pacijenta sa ovim oboljenjem [4-6]. U našem prikazu predstavljen je pacijent sa HBI koji je hirurški lečen u našoj ustanovi.

\section{Prikaz slučaja}

Pacijentkinja starosti 67 godina, koja je na hemodijalizi unazad 2 godine, pregledana je u Centru za endokrinu hirurgiju KCS radi donošenja odluke o operativnom lečenju. Na pregledu je kod pacijentkinje detektovana palpabilna tumorska promena u vratu u predelu levog lobusa štitaste žlezde. Vrednost kalcemije iznosila je $2,81 \mathrm{mmol} / \mathrm{L}$, kreatinina $416 \mu \mathrm{mol} / \mathrm{L}$, a nivo uree bio je $21 \mathrm{mmol} / \mathrm{L}$. Pregledom dokumentacije uočeno je da je godinu dana ranije nivo PTH iznosio 1337 ng/L, kada su se prvi put javile tegobe u vidu bolova u kostima i svraba po koži, a na dan pregleda vrednost PTH bila je $1022 \mathrm{ng} / \mathrm{L}$. Ultrazvučnom dijagnostikom opisana je izoehogena promena lateralno od levog lobusa štitaste žlezde promera 27x29x29 mm. Na MIBI scintigrafiji opisano je pojačano nakupljanje radiofarmaka u predelu donje desne paratiroidne žlezde, a scintigrafija celog tela nije pokazala nikakvo patološko nakupljanje radiofarmaka u ostalim tkivima.

U ličnoj anamnezi pacijentkinje prisutne su prethodne urološke operacije: operacija uklanjanja kamena iz uretera, potom desna nefrektomija i parcijalna leva nefrektomija zbog Renal Cell Carcinoma (RCC), nakon toga je urađena još jedna parcijalna resekcija preostalog dela levog bubrega. Nakon poslednje urološke operacije dolazi do pada glomerulske filtracije, a nakon dve godine od operacije pacijentkinja je započela lečenje hemodijalizom. Od komorbiditeta kod pacijentkinje je, pored hipertenzije, bila prisutna dijagnoza hronične limfocitne leukemije. 
Operativno lečenje je sprovedeno u roku od 24 časa nakon hemodijalize. Intraoperativno, zbog tumorske infiltracije, preparacija tkiva i pothiodnih mišića vrata bila je veoma teška. U toku preparacije došlo je do povrede leve unutrašnje jugularne vene koja je odmah suturirana. Nakon uspešne identifikacije donje leve paratiroidne žlezde, uočeno je da je ona čvrsto adherirana za levi lobus štitaste žlezde. Paratiroidea, koja je bila promera oko $4 \mathrm{~cm}$, ekstirpirana je zajedno sa ipsilateralnim lobusom štitaste žlezde. Zbog nejasne lokalizacije levog rekurentnog nerva, a nakon eksploracije vrata i identifikacije ostalih paratiroidnih žlezda koje su izgledale uredne veličine, kao i da nije bilo prisutne patološke limfonodopatije operativno lečenje je završeno. Tumor je

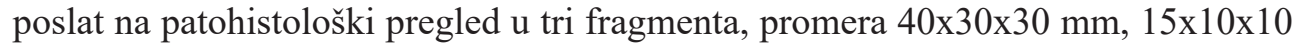
$\mathrm{mm}$ i $10 \times 5 \times 5 \mathrm{~mm}$, a težina preparata iznosila je 10 gr. Na osnovu kapsularne invazije, nekroze i mitotskih figura patohistološki je potvrđena dijagnoza paratiroidnog carcinoma (Slika 1). Istog dana nivo PTH je pao na $257 \mathrm{~g} / \mathrm{L}$, a dan nakon operacije na $56 \mathrm{ng} / \mathrm{L}$. Serumski nivo kalcijuma iznosio je 2,67 mmol/L, a neorganskog fosfata 2,02 mmol/L. Tri meseca nakon operativnog lečenja nivo PTH iznosio je $21 \mathrm{ng} / \mathrm{L}$, vrednosti kalcemije $2,59 \mathrm{mmol} / \mathrm{L}$, a vrednost neorganskog fosfata iznosila je 1,1 mmol/L. U terapiju je uveden Levotiroksin, a na narednoj kontroli FT4 i TSH su u referentnom opsegu.

Slika 1. A-kapsularna invazija; B-nekroza; $C$-tkivo štitaste žlezde; D-mitotske figure
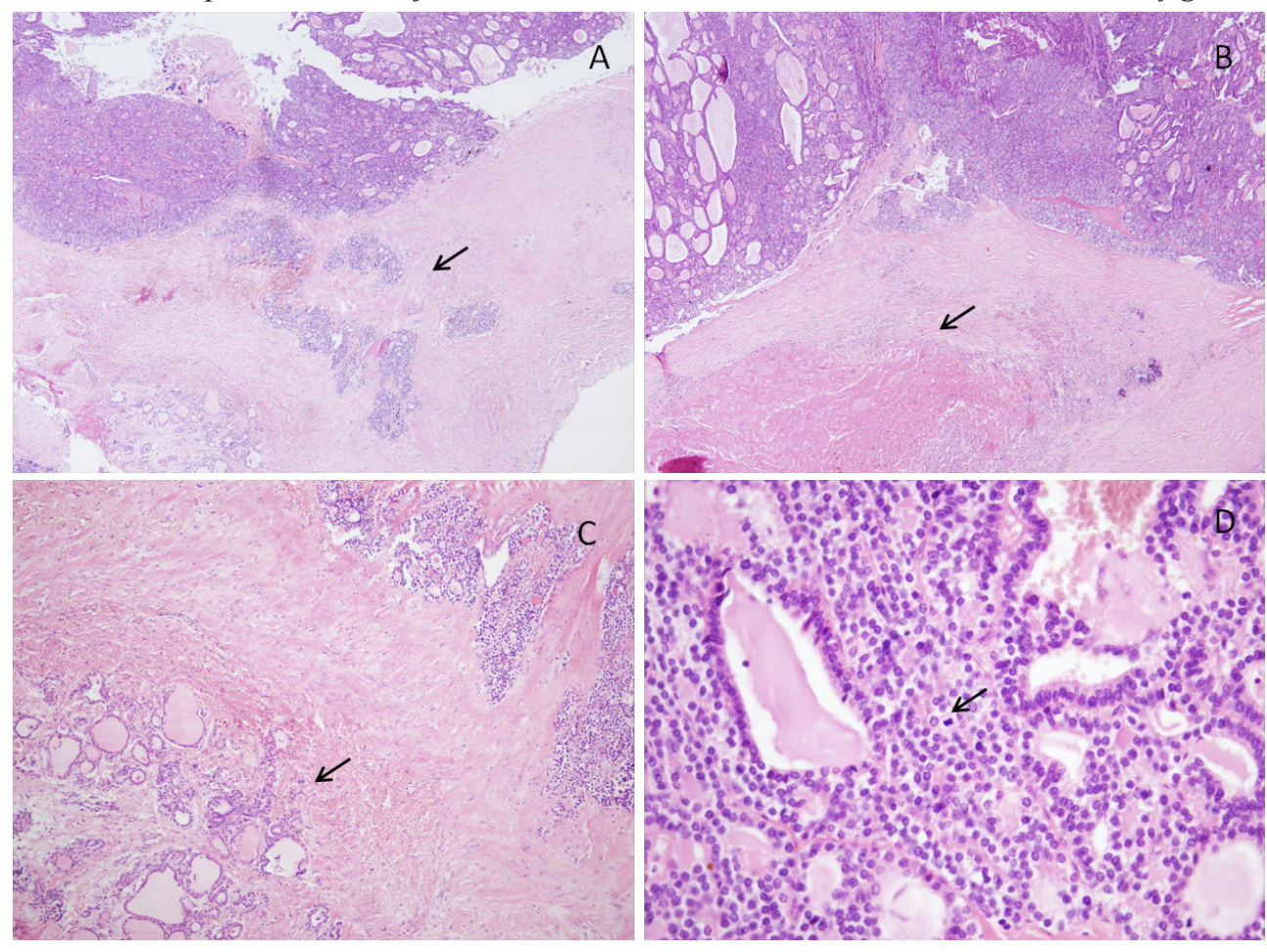


\section{Diskusija}

Karcinom paratiroidne žlezde je redak tumor endokrinih organa i jedan od najređih tumora u ljudskoj populaciji uopšte, sa incidencijom $0,005 \%$ svih karcinoma [1]. Preoperativno postavljanje dijagnoze paratiroidnog karcinoma predstavlja veliki izazov za lekare, a posebno je teško postaviti dijagnozu karcinoma kod pacijenata sa hroničnom bubrežnom insuficijencijom (HBI). Sumnju na karcinom budi infiltracija ipsilateralnog lobusa tiroidee, prisustvo lokoregionalnih metastaza. Potvrda dijagnoze karcinoma paratiroidee postavlja se na definitivnom patohistološkom pregledu, a poseban izazov za patologe predstavlja diferencijacija između atipičnog adenoma i paratiroidnog karcinoma [7]. Prvi karcinom paratiroidee kod pacijenata na HD opisao je Berland sa saradnicima 1982, nakon toga u literaturi je opisano još oko 35 slučajeva paratiroidnog karcinoma kod pacijenata sa HBI [4-6; 8-30].

Paratiroidni karcinom kod pacijenata na HD može da se javi u bilo kojoj uzrasnoj dobi. Tseng i saradnici su objavili najmlađeg pacijenta koji je imao 20 godina, dok je najstariji pacijent imao 75 godina, kako su objavili Jayawardene i saradnici $[18,20]$. Naš pacijent imao je 67 godina. Odnos polova kod karcinoma paratiroidne žlezde u sklopu primarnog hiperparatiroidizma je 1:1, dok kod pacijenata na HD postoji predominacija ženskog pola 1,57:1, razlog za ovaj disbalans među polovima nije objašnjen [31].

Kod $15 \%$ pacijenata nakon 10 godina hemodijalize indikovano je operativno lečenje, dok je nakon 20 godina provedenih na HD operacija indikovana kod oko $38 \%$ ovih pacijenata. Jedna od najčešćih indikacija za operativno lečenje je loš terapijski odgovor na kalcimimetike i analoge vitamina D [32]. Iako nema čvrstih dokaza za to, možemo se složiti sa Berlandom i saradnicima da produžena stimulacija, hiperfosfatemija, kao i povišene vrednosti serumskog parathormona (PTH)., mogu da prouzrokuju neoplaziju ćelija paraštitastih žlezda [8]. U proseku, kod pacijenata na HD vrednosti serumskog PTH kreću se od 2 do 9 puta iznad gornje granice, a prateći smernice National Kidney Foundationa jedna od indikacija za operativno lečenje je vrednost PTH iznad 800 ng/L [33]. Najviše vrednosti PTH objavio je Cabane sa saradnicima, kod njihovog pacijenta vrednost PTH iznosila je $2287 \mathrm{ng} / \mathrm{L}$ [29]. Najviša vrednost PTH našeg pacijenta iznosila je $1337 \mathrm{ng} / \mathrm{L}$. U literaturi, hiperkalcemija je bila prisutna kod 17 pacijenata na HD koji su imali karcinom paratiroidee [4-6; 8-30]. Ovo nam ukazuje na činjenicu da, pored izraženo povišenih vrednosti PTH, ovi pacijenti često imaju i hiperkalcemiju koja je refraktorna na terapiju i dijalizu.

Nekoliko studija se bavilo pitanjem da li veličina paratiroidnih žlezdi može biti indikacija za operaciju kod pacijenata na $\mathrm{HD}$, pregledom literature došlo se do zaključka da je kritična veličina PT žlezdi, koja je ujedno i jedna od indikacija za operaciju, $1 \mathrm{~cm}$ i više u dijametru na ultrazvučnom pregledu (UZ) [34]. Veličina karcinoma PT žlezde našeg pacijenta iznosila je 2,9 cm na UZ-nom pregledu, dok je makroskopski 
veličina iznosila $4 \mathrm{~cm}$. Pored veličine, bitnu determinantu za sumnju na karcinom ima i težina žlezde. Kod pacijenata koji imaju sekundarni hiperparatiroidizam nekoliko patoloških studija objavilo je da je prosečna težina hiperplastinih paratiroidnih žlezdi između 1 i 3 grama [35, 36]. Težina žlezde naše pacijentkinje iznosila je 10 grama. Na osnovu toga zaključujemo da su veličina i težina takođe dva bitna prediktora za sumnju i potvrdu karcinoma paratiroidne žlezde.

Metastaze paratiroidnog karcinoma opisane su u literaturi, kod 2 pacijenta $\mathrm{u}$ jetri, dok je metastaza karcinoma u plućima opisana kod 9 pacijenata $[10,14,15,17$, $18,24,27]$. Khan i saradnici su objavili slučaj pacijenta koji je imao diseminovanu bolest sa metastazama u plućima i kostima [24]. Tominaga i saradnici su objavili rad u kome su opisali 5 pacijenata sa metastazama paratiroidnog karcinoma u plućima, od tih 5 pacijenata kod 4 parafibromin je bio pozitivan [27].

2002. godine opisana je HRPT2 mutacija, poznata i kao CDC73 koja uzrokuje hyperparathyroidism-jaw tumor (HPT-JT) sindrom i nasleđuje se autozomno dominantno [38]. Osobe sa ovom mutacijom imaju doživotni rizik od $15 \%$ za nastanak paratiroidnog karcinoma. Aktivacija na oba alela ili mutacija HRPT2 prijavljena je kod većine osoba sa karcinomom paratiroidee, dok je ova mutacija veoma retko opisana kod benignih promena paratiroidnih žlezdi [37]. Parafibromin, nuklearni protein koji nastaje kao product HRPT2 gena, ima veliku ulogu u patogenezi karcinoma paratiroidne žlezde, jer je njegov nedostatak primećen kod pacijenata kod kojih je potvrđen karcinom paratiroidee [27].

Hirurško lečenje pacijenata sa sekundarnim hiperparatiroidizmom obuhvata dva pristupa: subtotalna paratiroidektomija ili totalna paratiroidektomija sa autotransplantacijom jedne paratiroidne žlezde u podlakticu nedominantne ruke. Kod pacijenata kod kojih intraoperativno postoji sumnja na paratiroidni karcinom prihvatljiv vid lečenja predstavlja en-bloc resekcija tumora sa okolnim tkivom, ipsilateralnim lobusom štitaste žlezde i ekstirpacijom paratrahealnih limfnih nodusa [38].

U zaključku možemo reći da je dijagnozu paratiroidnog karcinoma teško postaviti kod bilo kog pacijenta, a posebno kod pacijenata sa sekundarnim hiperparatiroidizmom. Sumnju na karcinom treba da nam pobudi palpabilna tumorska masa u vratu, prisustvo simptoma poput svraba i bolova u kostima, perzistentno povišene vrednosti kalcemije, i ekstremno visoke vrednosti PTH. Danas je lokalizacija PT žlezdi olakšana ne samo scintigrafskim snimanjem već i ultrazvučnom vizuelizacijom i kompjuterskom tomografijom (CT). Pored toga, CT i scintigrafija su dobre dijagnostičke metode kod pacijenata kod kojih postoji sumnja na ektopično tkivo paratiroidee ili sumnje na metastatsku bolest. Hirurško lečenje (subtotalna paratiroidektomija) je jedini izbor lečenja kod ovih pacijenata i sastoji se u uklanjanju ne samo karcinoma paratiroidee već i ispilateralnog lobusa štitaste žlezde kao i ekstirpacije limfnih nodusa, ukoliko je potrebno. S obzirom na raritet ovog oboljenja njegovo lečenje zahteva iskusnog endokrinog hirurga. 


\section{Reference}

1. Hundahl, SA, Fleming, ID, Fremgen, AM, Menck, HR. Two hundred eighty-six cases of parathyroid carcinoma treated in the U.S. between 1985-1995: a National Cancer Data Base Report. The American College of Surgeons Commission on Cancer and the American Cancer Society. Cancer 1999; 86: 538- 44.

2. Bossola M, Tazza L, Ferrante A, Giungi S, Carbone A, Gui D, et al. Parathyroid carcinoma in a chronic hemodialysis patient: case report and review of the literature. Tumori. 2005; 91: 558-62.

3. Zivaljevic V, Zivic R, Diklic A, Bukvic B, Tatic S, Kazic M et al. Parathyroid carcinoma in primary hyperparathyroidism: single institution experience. Eur Surg. 2012; 44:394-399.

4. Iwamoto N, Yamazaki S, Fukuda T, Kondo M, Yamamoto N, Ono T et al. Two cases of parathyroid carcinoma in patients on long-term hemodialysis. Nephron,1990; 55: 429-431.

5. Rademaker P, Meijer S, Oosterhuis JW, Vermey A, Zwierstra R, Hem G, Geerlings W. Successful surgical treatment of parathyroid carcinoma in two haemodialysis patients. Nephrol Dial Transplant, 1990; 5: 545-548.

6. Fuster D, Torregrosa JV, Esteve V, Ybarra J, Sabater L, Alós L, et al. Parathyroid carcinoma associated to secondary hyperparathyroidism in patients on dialysis: Two cases reports. Nefrologis. Vol. 27. Número 2. 2007. 27(2): 209-13.

7. Christakis I, Bussaidy N, Clarke C, et al., Differentiating atypical parathyroid neoplasm from parathyroid cancer, Ann. Surg. Oncol. 23. 2016; 2889-2897.

8. Berland Y, Olmer M, Lebreuil G, Grisoli J. Parathyroid carcinoma, adenoma and hyperplasia in a case of chronic renal insufficiency on dialysis. Clin Nephrol, 1982. 18: $154-158$.

9. Anderson BJ, Samaan NA, Vassilopoulou-Sellin R, Ordonez NG, Hickey RC. Parathyroid carcinoma: features and difficulties in diagnosis and management. Surgery, 1983; 94: 906-915.

10. Ireland JP, Fleming SJ, Levison DA. Parathyroid carcinoma associated with chronic renal failure and previous radiotherapy to the neck. J Clin Pathol, 1985. 38: 1114-1118.

11. Sherlock DJ, Newman J, Holl-Allen RT. Parathyroid carcinoma presenting as tertiary hyperparathyroidism. Postgrad Med J, 1985; 6: 243-244.

12. Krishna GG, Mendez M, Levy B, Ritchie W, Marks A, Narins RG: Parathyroid carcinoma in a chronic hemodialysis patient. Nephron, 1985; 52: 194-195.

13. Kodama M, Ikegami M, Imanishi M, Uemura T, Takada M, Kohri K et al. Parathyroid carcinoma in a case of chronic renal failure on dialysis. Urol Int, 1989; 44: 110-112.

14. Tominaga Y, Numano M, Uchida K, Sato K, Asano H, Haba Tet al. Lung metastasis from parathyroid carcinoma causing recurrent renal hyperparathyroidism in a hemodialysis patients: report of a case. Surg Today, 1995; 25: 984-986.

15. Miki H, Sumitomo M, Inoue H, Kita S, Monden Y. Parathyroid carcinoma in patients with chronic failure on maintenance hemodialysis. Surgery, 1996; 120: 897-901. 
16. Liou MJ, Lin JD, Huang MJ, Huang JY, Hsueh C, Jeng LB. Parathyroid carcinoma with postoperative prolonged hypocalcemia in a patient with chronic renal failure. $\mathrm{J}$ Formos Med Assoc, 1996; 95: 337-341.

17. Djema AI, Mahmoud MD, Collin P, Heymann MF. Tertiary hyperparathyroidism: parathyroid cancer with liver metastases in a hemodialyzed patient. Nephrologie, 1998; 19: $121-123$.

18. Tseng CC, Huang JJ, Wang MC, Lan RR, Sung JM, Chen FF. Parathyroid carcinoma with multiple lung metastases. Nephrol Dial Transplant, 1999; 14: 449-451.

19. Takami H, Kameyama K, Nagakubo I: Parathyroid carcinoma in a patient receiving long-term hemodialysis. Surgery, 1999; 125: 239-240.

20. Jayawardene S, Owen WJ, Goldsmith: Parathyroid carcinoma in a dialysis patient. Am J Kidney Dis, 2000; 36: 26-30.

21. Kuji T, Kitamura H, Yasuda G, Umemura S, Kimura T, Shimizu S et al. Different pathological findings in each of four parathyroid glands in a long-standing hemodialysis patient. Clin Nephrol, 2000; 54: 413-417.

22. Zivaljevic V, Krgovic K, Tatic S, Havelka M, Dimitrijevic Z, Diklic A, et al. Parathyroid cancer in a hemodialysis patient: a case report. Tumori. 2002; 88(5): 430-2.

23. Srouji IA, Resouly IA, Path FR. Case of thymic parathyroid carcinoma in a hemodialysis patient: application of tumor chemosensitivity testing. J Laryngol Otol, 2004. 118: 162-164, 2004.

24. Khan MW, Worcetser EM, Straus FH, Khan S, Staszak V, Kaplan E. Parathyroid carcinoma in secondary and tertiary hyperparathyroidism. J Am Coll Surg, 2004; 199: 312-319.

25. Falvo L, Catania A, Palermo S, Sorrenti S, Bonifazi AP, De Stefano M et al. Bilateral synchronous parathyroid carcinoma in a patient on long-term hemodialysis: presentation of a rare clinical case and review literature. Int Surg. 2005 Jan-Mar; 90(1): 18-22.

26. Diaconescu MR, Glod M, Costea I, Grigorovici M, Covic A. Parathyroid carcinoma in a patient on hemodialysis for renal failure. Rev Med Chir Soc Med Nat Iasi. 2006;110(1):152-6.

27. Tominaga Y, Tsuzuki T, Matsuoka S, Uno N, Sato Tet al. Expression of parafibromin in distant metastatic parathyroid tumors in patients with advanced secondary hyperparathyroidism due to chronic kidney disease. World J Surg. 2008 May; 32(5): 815-21.

28. Ardalan MR Parathyroid carcinoma in hemodialysis patients; it should not be diagnosed as a thyroid nodule. Journal of Parathyroid Disease 2013; 1(2): 25-26.

29. Cabané P, Gac P, Alvo A, Rodriguez F, Eugenia M, et al. Mediastinal Paratthyroid Carcinoma in A Patient with Chronic Kidney Disease in Hemodialysis. Endocrinol Metab Int J. 2016; 3(3): 00047.

30. Pappa A, Hackaman T, Simultaneous Incidental Parathyroid Carcinoma and Intrathyroid Parathyroid Gland in Suspected Renal Failure Induced Hyperparathyroidism. Surg J 2017; 3: e23-e24.

31. Hundahl, SA, Fleming, ID, Fremgen, AM, Menck, HR. Two hundred eighty-six cases of parathyroid carcinoma treated in the U.S. between 1985-1995: a National Cancer 
Data Base Report. The American College of Surgeons Commission on Cancer and the American Cancer Society. Cancer 1999; 86: 538- 44.

32. Schneider R, Slater EP, Karakas E, Bartsch DK, Schlosser K. Initial parathyroid surgery in 606 patients with renal hyperparathyroidism. World J Surg, 2012; 36: 318-326.

33. Yuen NK, Ananthakrishnan S, Campbell MJ. Hyperparathyroidism of Renal Disease. Perm J. 2016; 20(3): 15-127.

34. Goto S, Komaba H, Fukagawa M. Pathophysiology of parathyroid hyperplasia in chronic kidney disease: preclinical and clinical basis for parathyroid intervention. NDT Plus. 2008; 1(Suppl 3.): iii2-iii8.

35. Roychowdhury M. Anatomy and histology. Pathology Outlines. com website. https:// www.pathologyoutlines.com/topic/parathyroidanatomy.html.

36. Grimelius L, Akerstrom G, Johansson H, Bergstrom R. Anatomy and histopathology of human parathyroid glands. Pathol Annu 1981; 16: 1-24.

37. Gill AJ. Understanding the genetic basis of parathyroid carcinoma. Endocr Pathol. 2014 Mar; 25(1): 30-4.

38. Schulte K-M, Talat N. Diagnosis and management of parathyroid cancer. Nat Rev Endocrinol. 2012; 8: 612-22. 